\title{
Comparative Study on Molecular Weight of Konjac Glucomannan by Gel Permeation Chromatography-Laser Light Scattering-Refractive Index and Laser Light-Scattering Methods
}

\author{
Mei Xu, ${ }^{1,2}$ Dong-Sheng Li, ${ }^{1,2}$ Bin Li, ${ }^{3}$ Chao Wang, ${ }^{1,2}$ Yu-Peng Zhu, \\ Wen-Ping Lv, ${ }^{1,2}$ and Bi-Jun Xie ${ }^{3}$ \\ ${ }^{1}$ Key Laboratory of Fermentation Engineering (Ministry of Education), Hubei University of Technology, Wuhan 430068, China \\ ${ }^{2}$ Research Center of Food Fermentation Engineering and Technology of Hubei, Wuhan 430068, China \\ ${ }^{3}$ College of Food Science \& Technology, Huazhong Agricultural University, Wuhan 430070, China
}

Correspondence should be addressed to Chao Wang; wangchao5412@163.com

Received 22 June 2012; Revised 24 August 2012; Accepted 29 August 2012

Academic Editor: Jisheng Pan

Copyright (c) 2013 Mei Xu et al. This is an open access article distributed under the Creative Commons Attribution License, which permits unrestricted use, distribution, and reproduction in any medium, provided the original work is properly cited.

\begin{abstract}
The gel permeation chromatography, combined with laser light scattering and refractive index (GPC-LLS-RI) online method and laser light scattering (LLS) single method, researched the weight-average molecular weight (Mw) of konjac glucomannan (KGM) in this paper. The results show that the determination results of molecular weight of KGM are similar by two method, the molecular weight of KGM is $2.476 \times 10^{5} \mathrm{~g} / \mathrm{mol}$ by online method measured, and it is $2.508 \times 10^{5} \mathrm{~g} / \mathrm{mol}$ by single method measured, compared with only $1.3 \%$ difference between the two methods. At the same time, the molecular weight distributions of KGM and conformation index were analyzed by online method, while the second virial coefficient $\left(A_{2}\right)$ that characterizes the interaction between KGM molecules and solvent molecules was acquired by single method, which can provide reliable foundation for the molecular chain morphology research of KGM.
\end{abstract}

\section{Introduction}

Konjac glucomannan (KGM) is a water-soluble heteropolysaccharide $[1,2]$ derived from tubers of the Araceae plant. It is composed of 1,4-linked $\beta$-D-mannopyranose and $\beta$-Dglucopyranose units in a molar ratio of $1.6: 1$ with a low degree of acetyl groups at the side chain C-6 position and having a molecular weight on average of $0.67-1.9$ million [3]. It has been generally used in food [4], film formation, chemical engineering, and biomedical applications [59].

Laser light scattering is an important, noninvasive tool. The two different techniques commonly employed are static and dynamic light scattering. When light passes through biopolymers solution, depending on the optical parameters of the system, part of the light will be scattered. Polymers are formated oscillating dipole, forced vibration, issue of scattered light, determined the molecular weight, chain form, concentration, light-scattering angle, and refractive index increment $(\mathrm{d} n / \mathrm{d} c)$.

Properties of polysaccharide are closely related to molecular weight, conformation, and the degree of solvent. Usual methods for molecular weight have been reported including viscosity methods and gel permeation chromatography. However viscosity-average molecular weight of viscosity methods makes mistakes, conformation similarity of standard sample is calibrated.

Light-scattering method has overcame the weaknesses of viscosity methods and gel permeation chromatography, therefore it has become an important research tool.

Recently gel permeation chromatography, combined with laser light scattering and refractive index (GPC-LLS-RI) online method and laser light-scattering (LLS) single method, has analysed molecular weight besides weight-average molecular weight $(\mathrm{Mw})$, index of conformation $(\beta)$, and the second coefficient $\left(A_{2}\right)$, etc. 
At present, molecular weight and its distribution of KGM are measured with GPC-LLS-RI. Minority study of less molecular weight and $A_{2}$ is determined of LLS. Moreover a comparison of molecular weight of konjac glucomannan by GPC-LLS-RI and LLS has singularity been reported [10]. In this paper, compare molecular weight of KGM utilization of GPC-LLS-RI and LLS by static laser light scattering.

\section{Material and Methods}

2.1. Material. The konjac glucomannan samples were obtained from North Food Co. (Shanghai County, China) and used without further purification. The other reagents were A.R.

2.2. Preparation of KGM. Preparation of KGM according to Li and Xie [10]. KGM was extracted and purified from the tuber of the Araceae plant. Konjac tubers were sliced to about $8 \mathrm{~mm}$ in thickness and then dried under drying oven at $60^{\circ} \mathrm{C}$ for about $8 \mathrm{~h}$. The dried sheets of konjac were pulverized by Grinder. The crude flour was immersed in $50 \%(\mathrm{v} / \mathrm{v})$ aqueous methanol solutions for $4 \mathrm{~h}$ and then dried at $70^{\circ} \mathrm{C}$. The raw konjac flour was extracted with benzene absolute alcohol $(4: 1 \mathrm{v} / \mathrm{v})$ and trichloromethane-n-butanol for 5 times, respectively. The fat- and protein-extracted flour was dissolved with distilled water and heated at $40^{\circ} \mathrm{C}$ for $2 \mathrm{~h}$, after cooling to room temperature, the hydrosol of KGM was centrifuged at $10,000 \mathrm{rpm}$ for $40 \mathrm{~min}$. Then acetone was added to the supernatant and stirred. After filtered with $120 \mathrm{~m}$ sieve cloth, the white cotton-like precipitate was squashed and dried by vacuum freeze-dry. So the KGM was obtained.

2.3. Equation of Laser Light Scattering for Polymer Solution. Due to light-scattering method, the correlation of concentration $(c)$, the scattering angle $(\theta)$, and the scattered light intensity $\left(I_{\theta}\right)$ were established. $M w, R g$, and $A_{2}$ were obtained by Debye theory:

$$
\frac{H c}{R(\theta)}=\frac{1}{\mathrm{Mw}}\left(1+\frac{16 \pi^{2}}{3 \lambda^{2}} R g^{2} \sin \frac{\theta}{2}+\cdots\right)+2 A_{2} c .
$$

Type: $H=4 \pi^{2} n_{0}^{2}(\mathrm{~d} n / \mathrm{d} c)^{2} / \mathrm{Na} \lambda^{4}, n_{0}$ is the refractive index of the solvent, $\lambda$ is true air incident light wavelength (nm), Na is Gadereau constants.

2.4. $\mathrm{d} n / \mathrm{d} c$. KGM was dissolved by $0.2 \mathrm{~mol} / \mathrm{L} \mathrm{NaNO}_{3}$ and $0.22 \mu \mathrm{m}$, then order aqueous solution of KGM into RI detector (Wyatt-Optilab rEx) in turn. The $\mathrm{d} n / \mathrm{d} c$ of KGM in $0.2 \mathrm{~mol} / \mathrm{L} \mathrm{NaNO}_{3}$ aqueous solution was $0.147 \mathrm{~mL} / \mathrm{g}$.

2.5. GPC-LLS-RI. The samples were determined by gel permeation chromatography combined with laser light scattering (Wyatt Technology Co., CA, USA) and refractive index. The analyses condition of GPC-LLS-RI: Mobile phase $0.2 \mathrm{~mol} / \mathrm{L} \mathrm{NaNO}_{3}$ aqueous solution, Chromatography gel columns (OhpakSB-805HQ), incident light $\lambda=690 \mathrm{~nm}$, $T=25^{\circ} \mathrm{C}$, speed $1.0 \mathrm{~mL} / \mathrm{min}, V=2.0 \mathrm{~mL}$, concentration

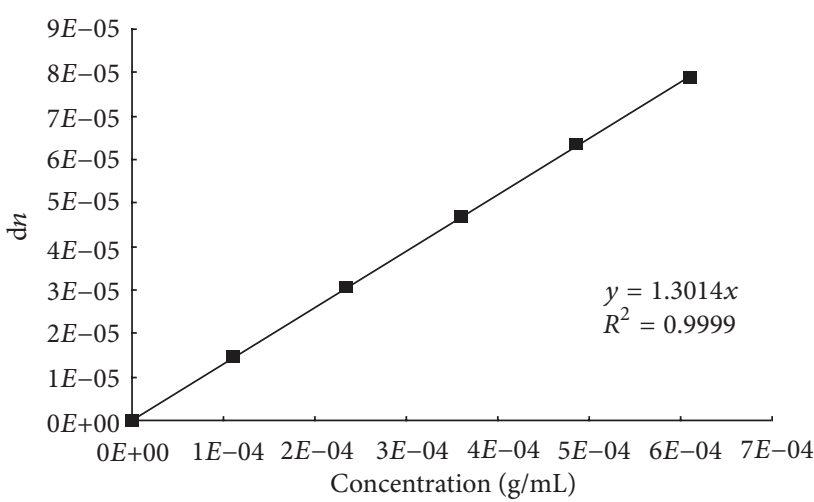

(a)

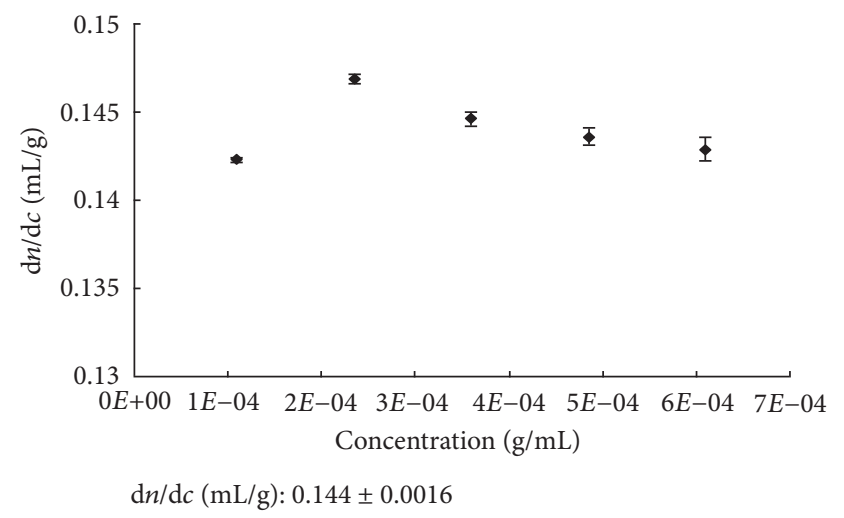

(b)

Figure 1: (a) The $\mathrm{d} n / \mathrm{d} c$ of KGM in $0.2 \mathrm{~mol} / \mathrm{L} \mathrm{NaNO}_{3}$ solution, (b) The $\mathrm{d} n / \mathrm{d} c$ of KGM in difference concentration.

of KGM was $1.0 \mathrm{mg} / \mathrm{mL}$. Sample data used AstraV5.1.5.3 software.

2.6. LLS. The samples were determined by laser light scattering. The analyses condition of LLS: Mobile phase $0.2 \mathrm{~mol} / \mathrm{L} \mathrm{NaNO}_{3}$ aqueous solution, Chromatography gel columns (OhpakSB-805HQ), incident light $\lambda=690 \mathrm{~nm}, \mathrm{~T}=$ $25^{\circ} \mathrm{C}$, speed $1.0 \mathrm{~mL} / \mathrm{min}, V=1.0 \mathrm{~mL}$. Sample data used AstraV5.1.5.3 software.

\section{Results and Discussion}

3.1. $\mathrm{d} n / \mathrm{d}$ c. $0.1 \mathrm{~g} \mathrm{KGM}$ was dissolved $0.2 \mathrm{~mol} / \mathrm{L} \mathrm{NaNO}_{3}$ solution, namely $1.0 \mathrm{mg} / \mathrm{mL} \mathrm{KGM}$ solution. And it was respectively diluted by $2.0 \times 10^{-4}, 4.0 \times 10^{-4}, 6.0 \times 10^{-4}$, and $8.0 \times$ $10^{-4} \mathrm{mg} / \mathrm{mL}$ solutions.

The ratio of concentration between refractive index of different macromolecules solutions and solvent was $\mathrm{d} n / \mathrm{d} c$. The value of $\mathrm{d} n / \mathrm{d} c$ had relation to solvent systems. Figure 1 showed $\mathrm{d} n / \mathrm{d} c$ value of $\mathrm{KGM}$ in $0.2 \mathrm{~mol} / \mathrm{L} \mathrm{NaNO}_{3}$ solution. And $\mathrm{d} n / \mathrm{d} c$ of KGM was $(0.144 \pm 0.0016) \mathrm{mL} / \mathrm{g}$ in $0.2 \mathrm{~mol} / \mathrm{L} \mathrm{NaNO}_{3}$ solution.

Note that the experiment data were repeated in Figure 1. 


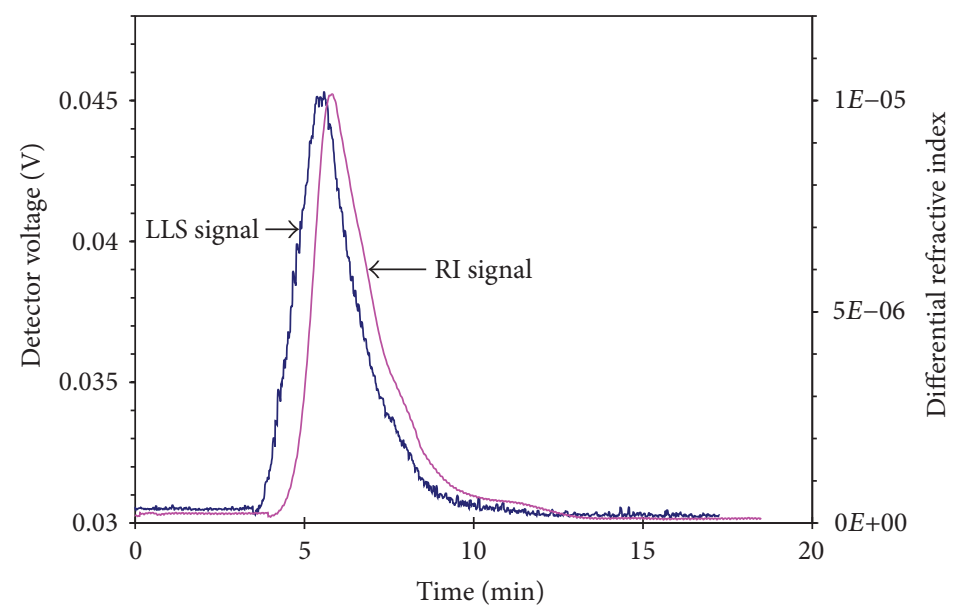

FIGURE 2: The eluent chromatograms of Molecular weigh of KGM by GPC-LLS-RI.

\subsection{GPC-LLS-RI Analysis}

3.2.1. Molecular Weight of KGM. GPC-LLS-RI went by laser detector in turn according to separate components from molecular weight size. Differences of intensity were corresponding to its composition.

In Figure 2, analyse of curve fitted better from LLS detectors and RI detectors. Distribution of KGM molecular weight was a single peak by gel permeation chromatography combined with laser light scattering and refractive index, $\mathrm{Mw} / \mathrm{Mn}=1.201, \mathrm{Mw}=2.476 \times 10^{5}$, and $\mathrm{Mn}=2.016 \times$ $10^{5}$. Such a result indicated that KGM was a kind of polysaccharide whose molecular weight distribution was much undispersed.

3.2.2. $\beta$ Value of KGM. Figure 3 showed the conformation diagram of KGM by GPC-LLS-RI. According to the relationship between $\mathrm{Mw}$ and $\mathrm{Rg}$, statistical analysed stretched state of polymer solution, namely, $\beta$ was correlation coefficient between $R n$ and Mw. When $\beta=0.3, \beta$ indicated that the polymer chain has curled into a ball. When $\beta=0.5-0.6$, $\beta$ indicated that semiflexible chain; $\beta$ indicated Rod-like or rigid links when $\beta=1.0$.

Experiment results indicated that $\beta$ was $0.33 \pm 0.02$, molecular chains of KGM have curled into spherical in aqueous solution. But KGM $\left(\mathrm{Mw}=2.508 \times 10^{6}\right)$ was semiflexible chain in aqueous solution from $\mathrm{B}$. Li et al. [10]. So experiment results could not maintain consistency about Li., This phenomenon was related to molecular weight.

\subsection{LLS Analysis}

3.3.1. Defined Peak Plots of KGM. Figure 4 showed that define peaks of KGM by LLS methods and samples (different concentrations) signals were proportional to concentration, and the experiment result have indicated that dilution of KGM solution was more reasonable.

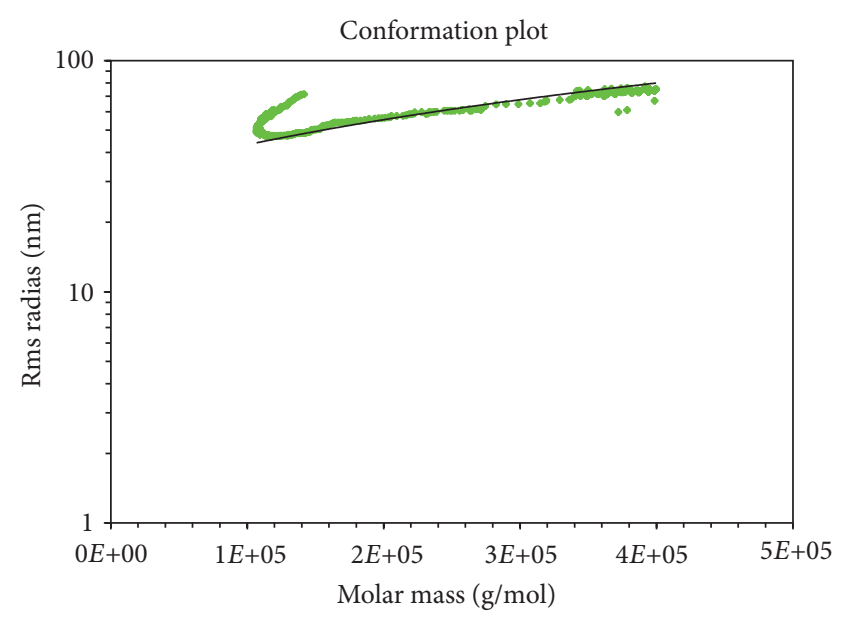

FIGURE 3: The relationship between $R g$ and Mw of KGM.

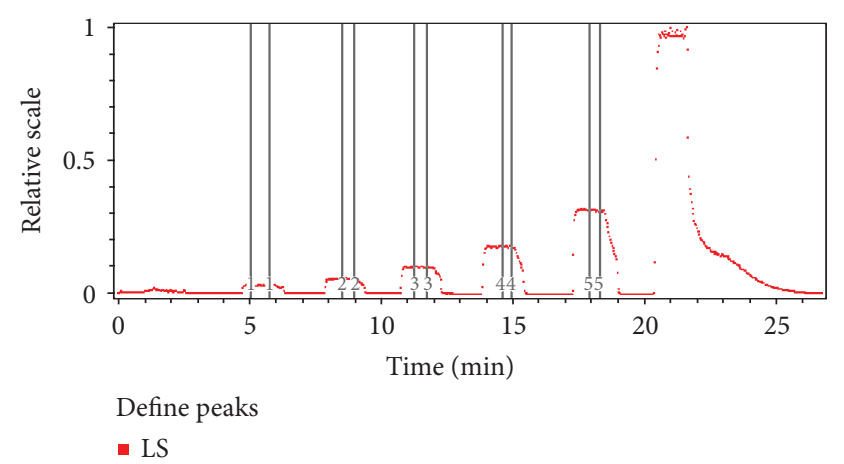

FIGURE 4: Define peaks of molecular weight of KGM by LLS.

3.3.2. Zimm Plot of KGM. Zimm was a series of straight lines according to the dependence of angle between different concentrations macromolecules and the strength of scattered light. Therefore weight-average molecular weight $(\mathrm{Mw})$ and the second coefficient $\left(A_{2}\right)$ have been deduced. Meanwhile 


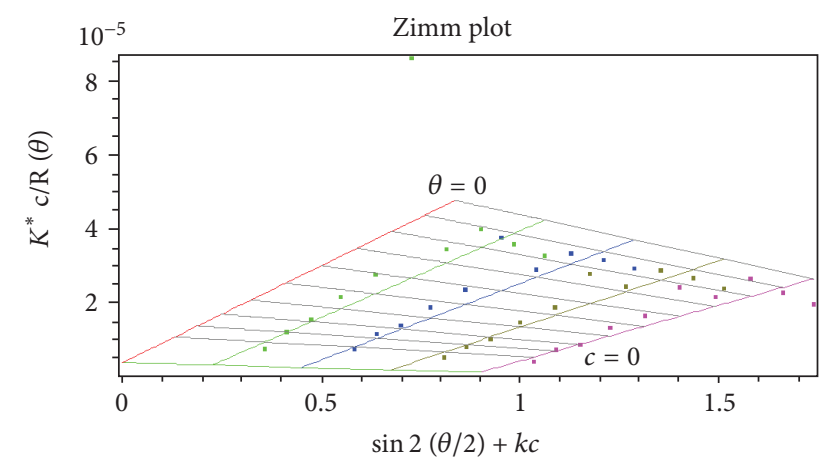

FIGURE 5: Zimm plot of KGM in water solution by LLS.

no solvent polarity restrictions expanded the correlation of study on several organic solvent system in analysis process.

Molecular weight of KGM was also determined only by LLS (uncombined with GPC). Figure 5 showed that Zimm plot of KGM in $\mathrm{NaNO}_{3}$ solution. Due to line intercept and slope of $c=0$ in Figure $5, \mathrm{Mw}=2.508 \times 10^{5}, \mathrm{Rg}=$ $60.4 \mathrm{~nm}$ separately; $A_{2}=(1.577 \pm 3.026) e^{-3}>0$ by $\theta=0^{\circ}$. Therefore it indicated that $0.2 \mathrm{~mol} / \mathrm{L} \mathrm{NaNO}_{3}$ was excellent solvent from KGM in accordance with the thermodynamic theory of polymer solutions ( $A_{2}>0$, benign solvents).

Though Mw/Mn and $\beta$ of KGM has been analysed by GPC-LLS-RI, organic solvent was not mobile phase in GPCLLS-RI method because of mobile phase restrictions for chromatography gel column. LLS (uncombined with GPC) method had overcome the second coefficient $\left(A_{2}\right)$, therefore it could research interactions of solvent between molecules of KGM.

KGMs have gradually been accepted as important food colloids. Molecular weight is one of their important quality indicators. Although both GPC-LLS-RI and LLS methods could determine molecular weight of KGM and enable purchasers and users, they could not evaluate accuracy of molecular weight. In this paper, Comparative study on molecular weight of konjac glucomannan by GPC-LLS-RI and LLS methods is evaluating accuracy of molecular weight and providing the theoretical basis for large-scale application development, controlling industrial production.

\section{Conclusion}

Above experiments have showed that $\mathrm{d} n / \mathrm{d} c$ value of KGM was $(0.144 \pm 0.0016) \mathrm{mL} / \mathrm{g}$ in $0.2 \mathrm{~mol} / \mathrm{L} \mathrm{NaNO}_{3}$ solution only by LLS method, comparative molecular weight of KGM by GPC-LLS-RI and LLS (error was only 1.3\%), the results showed that $\mathrm{Mw}$ value of KGM was closely. Confidence of molecular weight of KGM was high.

\section{Acknowledgments}

The authors gratefully acknowledge the National Key Technology R\&D Program (2012BAD27B03) for their support of their work. Thanks are also due to members of the Key Laboratory of Fermentation Engineering (Ministry of Education),
Hubei University of Technology and the Research Centre of Food and Fermentation Engineering and Technology for technical assistance and valuable discussions in Hubei. The authors would like to thank Dr. Chao Wang of Department of Biology, Hubei University of Technology, Wuhan, China, for identifying the samples.

\section{References}

[1] K. Nishinari, "Konjac glucomannan," Developments in Food Science, vol. 41, pp. 309-330, 2000.

[2] K. Katsuraya, K. Okuyama, K. Hatanaka, R. Oshima, T. Sato, and K. Matsuzaki, "Constitution of konjac glucomannan: chemical analysis and ${ }^{13} \mathrm{C}$ NMR spectroscopy," Carbohydrate Polymers, vol. 53, no. 2, pp. 183-189, 2003.

[3] B. Li and B. Xie, "Synthesis and characterization of konjac glucomannan/poly(vinyl alcohol) interpenetrating polymer networks," Journal of Applied Polymer Science, vol. 93, no. 6, pp. 2775-2780, 2004.

[4] X. Wen, T. Wang, Z. Y. Wang, L. Li, and C. Z. Zhao, "Preparation of konjac glucomannan hydrogels as DNA-controlled release matrix," International Journal of Biological Macromolecules, vol. 42, no. 3, pp. 256-263, 2008.

[5] X. J. Zhang and F. T. Jiang, "Modification and application of konjac glucomannan," Chemistry and Biological Engineering, vol. 2, pp. 4-6, 2004.

[6] H. Q. Yu, Y. H. Huang, H. Ying, and C. B. Xiao, "Preparation and characterization of a quaternary ammonium derivative of konjac glucomannan," Carbohydrate Polymers, vol. 69, no. 1, pp. 29-40, 2007.

[7] Y. Q. Zhang, X. Gan, B. J. Xie, and Y. Xiao, "Optimization of the technology for sulfated modification of konjac glucomannan gel beads," Transactions of the Chinese Society of Agricultural Engineering, vol. 21, no. 6, pp. 140-143, 2005.

[8] Y. Q. Zhang, X. Gan, and B. J. Xie, "Advance in the applications of konjac glucomannan and its derivatives," Carbohydrate Polymers, vol. 60, no. 1, pp. 27-31, 2005.

[9] C. M. Niu, W. H. Wu, Z. Wang, S. Li, and J. Wang, "Adsorption of heavy metal ions from aqueous solution by crosslinked carboxymethyl konjac glucomannan," Journal of Hazardous Materials, vol. 141, no. 1, pp. 209-214, 2007.

[10] B. Li and B. J. Xie, "Single molecular chain geometry of konjac glucomannan as a high quality dietary fiber in East Asia," Food Research International, vol. 39, no. 2, pp. 127-132, 2006. 

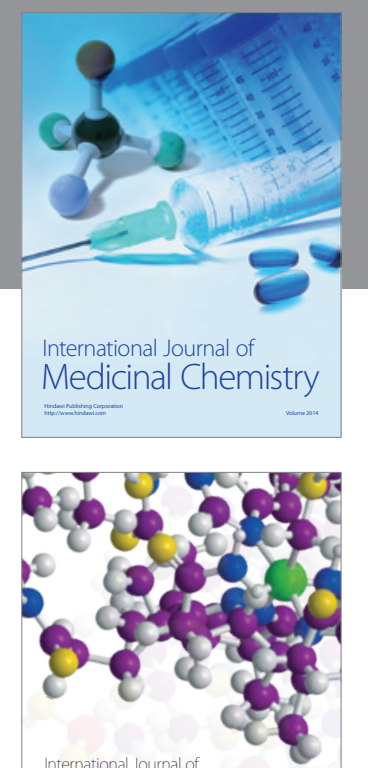

\section{Carbohydrate} Chemistry

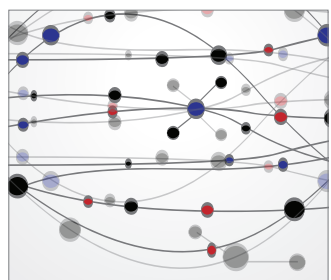

The Scientific World Journal
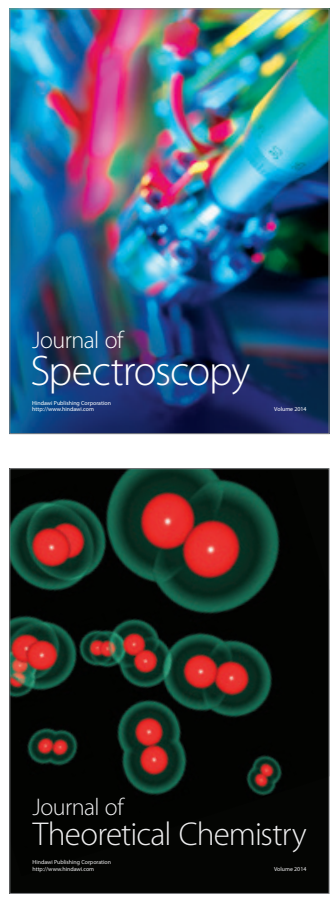
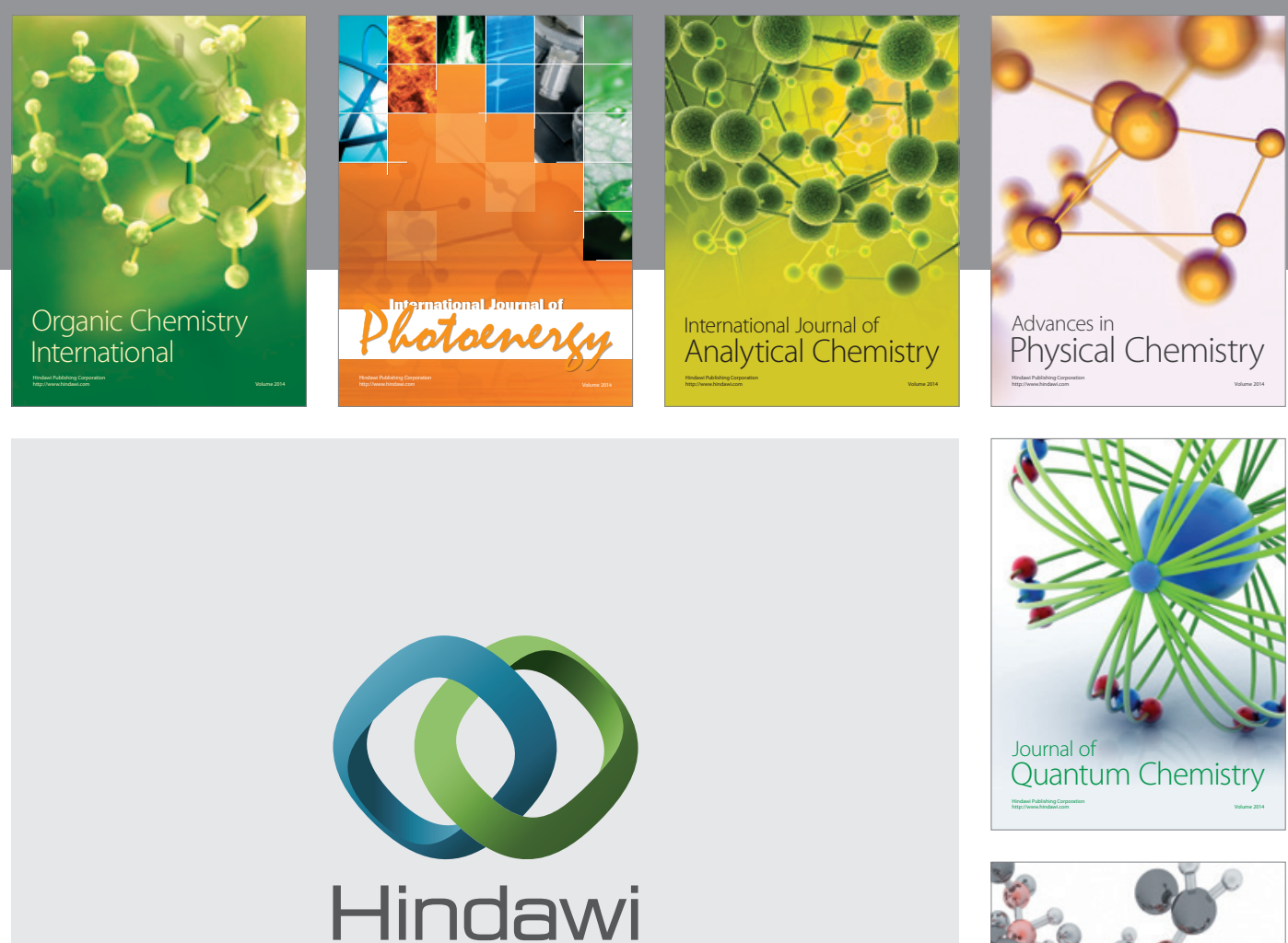

Submit your manuscripts at

http://www.hindawi.com

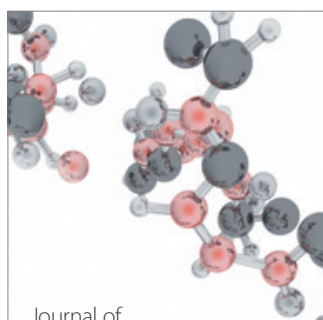

Analytical Methods

in Chemistry

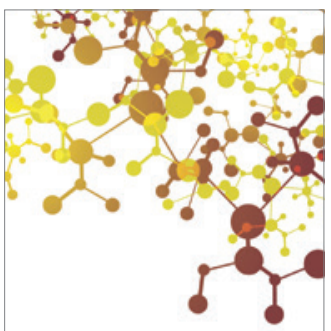

Journal of

Applied Chemistry

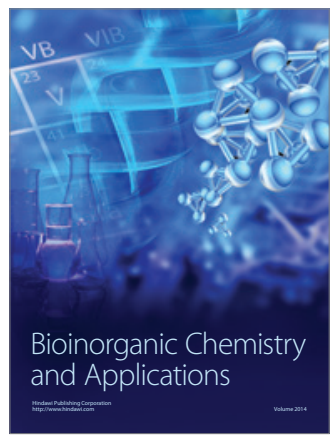

Inorganic Chemistry
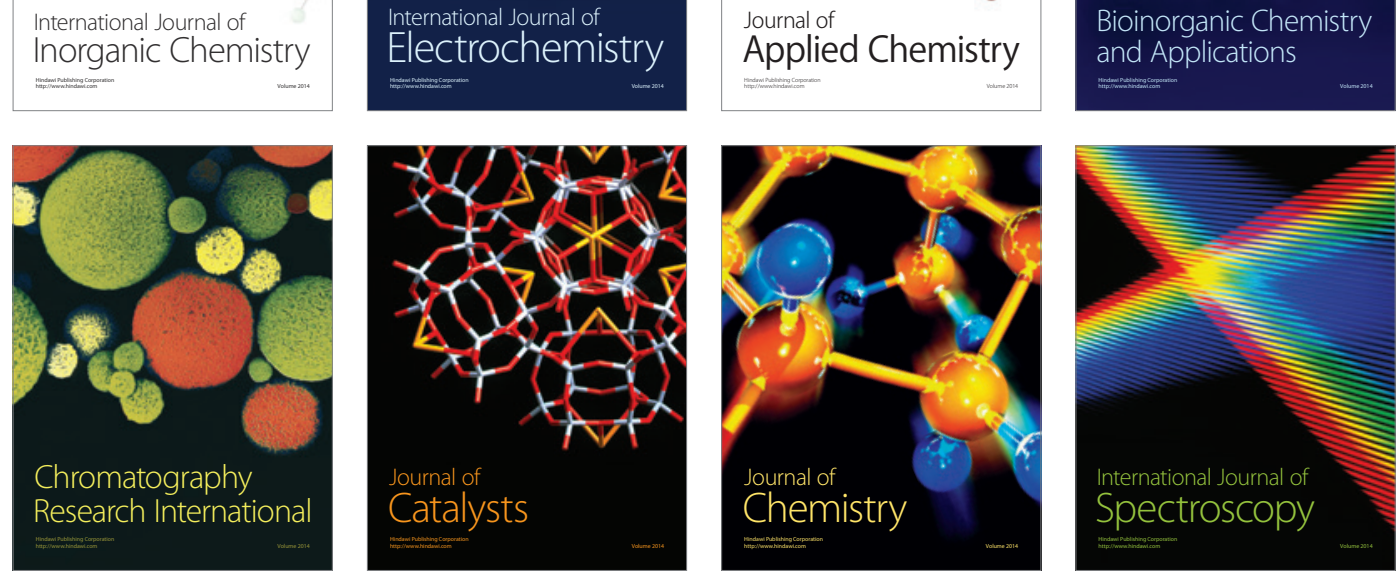